\title{
Review:
}

\section{A review of the chloride transport properties of cracked concrete: experiments and simulations*}

\author{
Chun-ping GU ${ }^{\dagger 1,2}$, Guang $\mathrm{YE}^{2}$, Wei SUN ${ }^{1,3,4}$ \\ ( ${ }^{1}$ School of Materials Science \& Engineering, Southeast University, Nanjing 211189, China) \\ ( ${ }^{2}$ Microlab, Faculty of Civil Engineering and Geosciences, Delft University of Technology, Delft 2628 CN, the Netherlands) \\ ( ${ }^{3}$ Jiangsu Key Laboratory of Construction Materials, Nanjing 211189, China) \\ $\left({ }^{4}\right.$ Collaborative Innovation Center for Advanced Civil Engineering Materials, Nanjing 211189, China) \\ 'E-mail: guchunpinghall@hotmail.com
}

Received Aug. 7, 2014; Revision accepted Jan. 4, 2015; Crosschecked Jan. 22, 2015

\begin{abstract}
Chloride transport property is very important for the durability and service life of reinforced concrete structures subjected to marine environments and de-icing salt. In reality, for different reasons, concrete structures are frequently cracked, and cracks can alter the chloride transport properties of concrete. Recently, several studies have been conducted by both experiment and simulation on the influence of cracks on the chloride transport properties of concrete. The aim of this paper is to review these research efforts. The experimental methods and simulation approaches on the chloride transport properties of cracked concrete are introduced. Detailed discussions on the findings from these experimental and simulation studies are given. The chloride transport properties of cracked concrete are influenced by various factors, such as crack geometry, concrete composition, and load condition. Research in this area is still on-going, and many problems need to be settled before proposing reliable models for predicting the service life of real cracked concrete structures in chloride environments. Hence, some further research topics are recommended. The influences of other factors, such as carbonation, freeze-thaw, fatigue, and saturation degree, on the transport properties of cracked concrete should be revealed.
\end{abstract}

Key words: Concrete, Crack, Chloride transport property, Experiment, Simulation doi: $10.1631 /$ jzus.A1400247

Document code: A

CLC number: TU528

\section{Introduction}

In an environment exposed to seawater or de-icing salt, chloride-induced corrosion of reinforcing steel is the most important deterioration mechanism of reinforced concrete structures. Under chloride attack, the reinforcing steel corrodes more easily (Mehta and Monteiro, 2006). The volume of the corrosion products is about four to six times larger than the steel (Mehta and Monteiro, 2006). This

\footnotetext{
* Project supported by the National Basic Research Program of China (No. 2009CB623203), the National Natural Science Foundation of China (No. 51378113), and the Fundamental Research Funds for the Central Universities (No. 3212002206), China

(D) ORCID: Chun-ping GU, http://orcid.org/0000-0003-4102-0350

(C) Zhejiang University and Springer-Verlag Berlin Heidelberg 2015
}

volume increase would induce internal tensile stresses in the cover concrete, resulting in cracking, delamination and spalling. Therefore, in the durability design of these structures, the most important factor that determines their service life is the chloride transport properties of the concrete.

Extensive studies have been conducted over the past decades to study the chloride transport properties of concrete. Most of the studies were carried out on sound and uncracked concrete (Zhang and Gjørv, 1996; Wang et al., 2005; Song et al., 2008; Pack et al., 2010). However, in most cases, cracks (microcracks) may exist in reinforced concrete structures for different reasons. A restrained volume change is one of the most common causes of cracks in concrete. Concrete will shrink during the hydration process. If 
the shrinkage is restrained, tensile stress will develop. Once the stresses exceed the tensile strength of the concrete, cracks will occur (Carino and Clifton, 1995). Cracks also can be induced by a temperature gradient between the interior and the exterior of concrete, resulting in tensile stresses on the exterior. If the tensile strength of the concrete is exceeded, cracking will emerge (ACI 224.1R-07, 2007). Thermally induced cracks are prone to occur in mass concrete. Durability problems also can lead to cracks, such as freeze-thaw action, alkali-aggregate reaction, sulfate ingress, and corrosion of reinforcement. Other reasons for concrete cracking could lie in poor construction practices, construction overloads, errors in design and externally applied loads (ACI 224.1R-07, 2007). The crack width in concrete may vary from microns to millimeters. In reinforced concrete structures, steel bars are provided to resist the tensile stress caused by service loads and may help to distribute the cracks and limit their width.

Cracks in concrete may act as flow channels for aggressive ions as chlorides, accelerating the rate of chloride ingress and hence the onset of corrosion (Djerbi et al., 2008). Therefore, in studies on the transport properties of concrete, cracks must be taken into account to reflect the practical working condition of reinforced concrete structures.

Several studies have focused on the effect of cracks on the chloride transport properties of concrete, using both experiments and numerical simulations (Rodriguez and Hooton, 2003; Kato et al., 2005; Sahmaran, 2007; Ismail et al., 2008; Wang et al., 2008; Audenaert et al., 2009a; 2009b; Ishida et al., 2009; Marsavina et al., 2009; Jin et al., 2010; Yoon and Schlangen, 2010; Wang and Ueda, 2011; Lu et al., 2012; Bentz et al., 2013; Šavija et al., 2013). This paper reviews these experimental findings and simulation methods. The experimental methods and results are first described and then some simulation approaches are introduced. Based on the review, some research prospects for both experimental and simulation studies are discussed.

\section{Experimental}

\subsection{Methods to induce cracks in concrete}

To study the chloride transport properties of cracked concrete, cracks have to be generated in a concrete specimen. There are two main methods to introduce cracks in concrete.

The first is to mimic cracks by saw-cutting (Rodriguez and Hooton, 2003) or by putting a plate as a mold of a crack into cast concrete (Marsavina et al., 2009). In general, artificial cracks are parallel walled and the widths and depths can be controlled precisely. This method can be used to study the influences of crack width and crack depth on the chloride transport properties of cracked concrete. However, these cracks are not realistic. The effects of tortuosity, connectivity and surface roughness of the cracks are impossible to study with this method.

The other method is to induce cracks by loading a concrete specimen. The main advantage of this method is that realistic cracks can be produced. Four widely used methods (Fig. 1) are summarized as follows: (1) The splitting method (Brazilian splitting test) (Rocco et al., 2001; Djerbi et al., 2008). For this method, linear variable displacement transducers (LVDTs) and a feedback displacement controlled machine are used. The crack width can be controlled by adjusting the target crack open displacement (COD). It is a very easy method to use, but the crack produced may be identical in width on both sides of the specimen (Wang et al., 1997). It is not a V-shaped crack, which would be more realistic. (2) The wedge splitting method (Leite et al., 2004; Pease et al., 2007; Löfgren et al., 2008), which is commonly used in fracture mechanics. This method is simple and can produce V-shaped cracks. Hence, it is also used in concrete research. (3) Three or four points bending (Gowripalan et al., 2000; Kato et al., 2005). It is carried out on prism or beam specimens. This method gives the most realistic cracks. Both single crack and multiple cracks can be generated. It can be used to study the chloride transport properties of cracked concrete under loading. (4) Expansive core method (Ismail et al., 2004; 2008; Šavija et al., 2013). Samples are subjected to controlled tensile cracking using a mechanical expansive core and external steel confinement rings. The cracks produced in this way are similar to those produced by the splitting method, i.e., almost parallel wall cracks, but the specimens under loading can be used for chloride penetration tests directly. In general, each method has its own advantages, and therefore, can be successfully used to study different influencing factors (Šavija and Schlangen, 2012). 


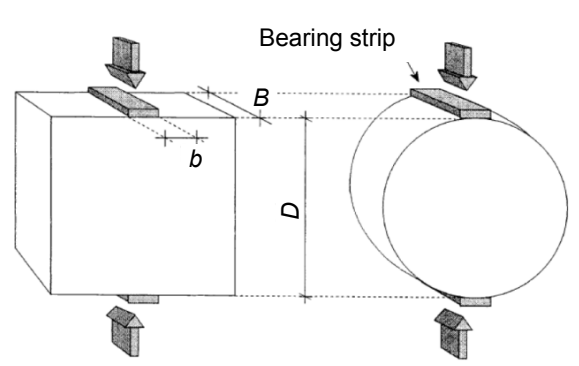

(a)

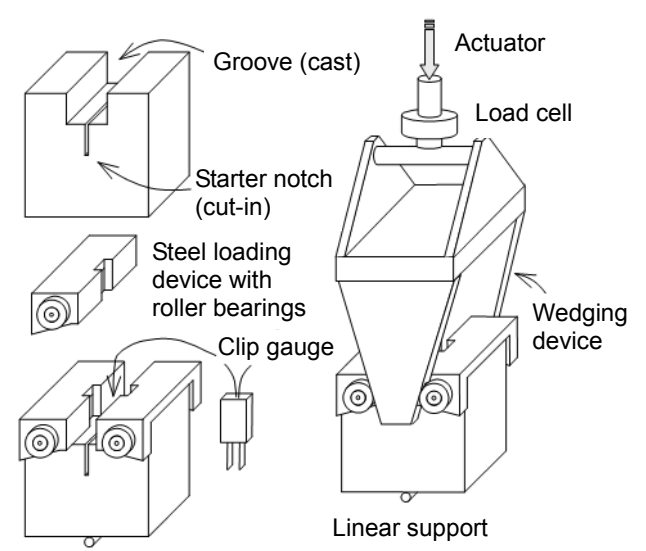

(b)

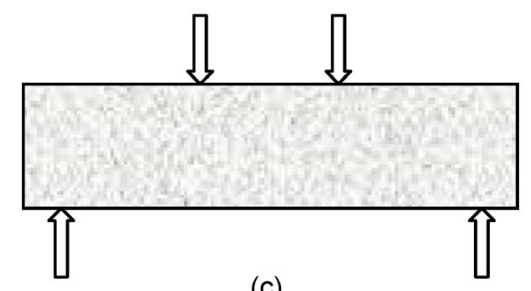

(c)

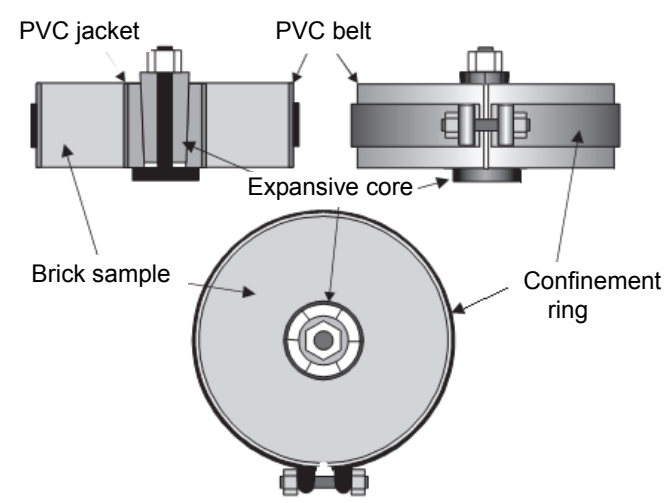

(d)

Fig. 1 Illustrations of methods used to induce cracks (a) Brazilian splitting method. Reprinted from (Rocco et al., 2001), Copyright 2001, with permission from Elsevier; (b) Wedge splitting method. Reprinted from (Löfgren et al., 2008), Copyright 2007, with permission from Springer; (c) Four point bending; (d) Expansive core method. Reprinted from (Ismail et al., 2008), Copyright 2008, with permission from Elsevier

\subsection{Methods to test the chloride transport prop- erties of cracked concrete}

The chloride transport process in concrete is usually governed by four mechanisms: diffusion, migration, permeation, and convention (Šavija et al., 2013). When the concrete is fully water saturated, it can be considered that chloride diffusion is the governing transport mechanism. Under non-saturated conditions, the transport of chlorides is a very complicated process, and is controlled by means of many combined mechanisms (Šavija et al., 2013). To simplify the studies on the chloride transport process in cracked concrete, specimens in experiments are usually saturated. In these circumstances, the chloride diffusion process in cracked concrete is the main concern.

Many methods have been published for determining the chloride transport properties of sound concrete. Some of them have been used to study the effect of cracks on chloride transport properties of concrete. The test methods can be divided into conventional methods and accelerated methods (Sillanpää, 2010). Conventional methods include, for example, the diffusion cell test (Sillanpää, 2010) and the immersion test (NT Building 443, 1995), generally representing the natural chloride diffusion process. The chloride diffusion process in concrete is controlled by Fick's law. Fick's first law applies to steady-state diffusion, and Fick's second law describes non-steady-state diffusion. Many studies have been conducted on the chloride transport process in cracked concrete using conventional diffusion methods (Gowripalan et al., 2000; Rodriguez and Hooton, 2003; Aiyastuti, 2005; Ismail et al., 2008; Yoon and Schlangen, 2010). Since diffusion is a very slow process, these methods are very timeconsuming, but can capture the realistic chloride diffusion process in concrete.

The chloride transport process in concrete also can be accelerated by an external electrical field. In this case, migration is considered as the major chloride transport mechanism. The movement of ions in a solution under an electrical field is governed by the Nernst-Planck equation, from which the chloride migration coefficient of concrete can be calculated. This is a fast method to determine the chloride transport properties of concrete. The test methods based on this principle include the non-steady-state 
migration test (NT Building 492, 1999) and the steady-state migration test (NT Building 355, 1997). Several authors have used these methods to study the effect of cracks on the chloride transport properties of concrete (Yoon et al., 2007; Djerbi et al., 2008; Marsavina et al., 2009; Audenaert et al., 2009a).

Detailed information on the principles and descriptions of the test methods used to determine the chloride transport properties of concrete can be found in (Sillanpää, 2010; Šavija and Schlangen, 2012).

\subsection{General results of experimental research}

The results of experimental studies show that the chloride transport properties of cracked concrete are influenced by various factors, such as the crack width, crack depth, concrete composition and the loading condition.

\subsubsection{Crack width}

Crack width is considered to be the most important factor that influences the chloride transport properties of cracked concrete. Many studies have been conducted on this subject. A general understanding of how crack width influences the chloride transport properties has been attained, but there is still variation in the results obtained from different experiments due to differences in the experimental methods.

The non-steady-state migration test and immersion method, which is also a non-steady-state test, were used by Ismail et al. (2008), Rodriguez and Hooton (2003), Marsavina et al. (2009), Audenaert et al. (2009a), and Yoon and Schlangen (2010; 2014). The test results are summarized in Table 1.
Djerbi et al. (2008) used a steady-state migration test to assess the influence of crack width on the chloride diffusion coefficient of cracked concrete. They found that the chloride diffusion coefficients of cracked samples increased with increasing crack width. For crack widths of $<80 \mu \mathrm{m}$, the diffusion coefficient of cracked concrete increased moderately compared with that of sound concrete, whereas for crack widths of $>80 \mu \mathrm{m}$, it increased rapidly. They calculated chloride diffusion coefficients in cracks with different crack widths. The results showed that the chloride diffusion coefficient in the crack increased linearly with increasing crack width from $30 \mu \mathrm{m}$ to $80 \mu \mathrm{m}$ and was almost constant when the crack width was about $80 \mu \mathrm{m}$ or more. The fitted relationship between the chloride diffusion coefficient in the crack and the crack width is shown in Eq. (1), which has been adopted for simulating the chloride diffusion process in the crack and in cracked concrete (Šavija et al., 2013).

$$
\left\{\begin{array}{c}
D_{\mathrm{cr}}=\left(2 \times 10^{-11} w_{\mathrm{cr}}-4 \times 10^{-10}\right) \mathrm{m}^{2} / \mathrm{s}, \\
30 \mu \mathrm{m} \leq w_{\mathrm{cr}} \leq 80 \mu \mathrm{m} ; \\
D_{\mathrm{cr}} \approx 1.4 \times 10^{-9} \mathrm{~m}^{2} / \mathrm{s} \\
w_{\mathrm{cr}} \geq 80 \mu \mathrm{m} .
\end{array}\right.
$$

Based on all these results, it can be concluded that the crack width has a great effect on the chloride transport properties of cracked concrete. When the crack width is smaller than a lower critical value, for example $<30 \mu \mathrm{m}$, the chloride transport process in the crack is very slow, and thus the crack width has almost no influence on the chloride transport process in

Table 1 Influence of crack width on the chloride transport properties of cracked concrete

\begin{tabular}{|c|c|c|c|c|}
\hline Reference & $\begin{array}{l}\text { Method to } \\
\text { produce cracks }\end{array}$ & $\begin{array}{l}\text { No obvious influence } \\
\text { (no diffusion occurs } \\
\text { along the crack path) }\end{array}$ & $\begin{array}{l}\text { Influenced by the } \\
\text { crack width }\end{array}$ & $\begin{array}{c}\text { Crack walls considered as } \\
\text { surfaces exposed to } \\
\text { chloride }\end{array}$ \\
\hline Ismail et al., 2008 & Expansive core method & $<0.03 \mathrm{~mm}$ & $0.08-0.1 \mathrm{~mm}$ & $>0.2 \mathrm{~mm}$ \\
\hline $\begin{array}{l}\text { Rodriguez and Hooton, } \\
2003\end{array}$ & Artificial cracks & - & - & $0.08-0.68 \mathrm{~mm}$ \\
\hline Marsavina et al., 2009 & Artificial cracks & - & - & $0.2-0.5 \mathrm{~mm}$ \\
\hline Audenaert et al., 2009a & $\begin{array}{l}\text { Three point bending } \\
\text { test and Brazilian } \\
\text { splitting test }\end{array}$ & - & $0-0.1 \mathrm{~mm}$ & $0.1-0.2 \mathrm{~mm}$ \\
\hline $\begin{array}{l}\text { Yoon and Schlangen, } \\
\text { 2010; } 2014\end{array}$ & Artificial cracks & $\begin{array}{c}<0.013 \mathrm{~mm} \text { for short } \\
\text { term test; } \\
<0.04 \mathrm{~mm} \text { for long } \\
\text { term test }\end{array}$ & - & - \\
\hline
\end{tabular}


cracked concrete; when the crack width is bigger than an upper critical value, for example $>80 \mu \mathrm{m}$, the crack walls act as exposed concrete surfaces, contributing only to lateral chloride diffusion. When non-steadystate diffusion or migration tests are applied, the crack width does not have much effect on the chloride penetration depth in cracked concrete. Only when the crack width is between the lower and upper values, for example $30 \mu \mathrm{m}$ and $80 \mu \mathrm{m}$, is the chloride transport process in the cracks and cracked concrete influenced by the crack width. However, there is still no consensus on the exact values of the lower and upper thresholds for the crack width. This is mainly owing to differences in crack geometry and concrete properties in the experiments.

\subsubsection{Crack depth}

Marsavina et al. (2009) studied the influence of crack depth on the chloride penetration process in concrete with non-steady-state migration tests. Artificial cracks were created in the specimens. Based on the experimental results, they concluded that the chloride penetration depth increased with an increasing (artificial) crack depth, and this effect was more pronounced with longer test durations. Similar results were also reported by Audenaert et al. (2009b).

\subsubsection{Concrete composition}

The influence of concrete composition on the chloride transport process in cracked concrete lies mainly in the self-healing effect. Concrete with a low water content contains a lot of unhydrated cement particles. When cracks occur and go through the unhydrated cement particles, the cement would contact with water directly and begin to rehydrate. Hydration products would form in the crack and block the crack to some extent, impeding the chloride transport process.

Şahmaran (2007) showed that when crack width was less than $50 \mu \mathrm{m}$, a significant amount of self-healing was observed within cracks exposed to sodium chloride solution for $30 \mathrm{~d}$. Yoon and Schlangen (2010) noticed that chloride penetration through a crack tended to decrease with time. They attributed this to the effect of self-healing. Jacobsen $e t$ al. (1996) studied the effect of cracking and healing on the chloride transport properties of ordinary con- crete using chloride migration tests. They found that the rate of chloride migration in self-healed concretes was reduced by $28 \%-35 \%$. Ismail et al. (2008) also showed that the self-healing potential of the mortar matrix could hamper chloride diffusion in a crack.

Although some primary results have been obtained, further research on the quantification of selfhealing effects on the chloride transport process in cracks is still necessary.

\subsubsection{Loading condition}

The chloride transport properties of concrete can be influenced also by the loading condition. The status of the concrete specimen under loading is quite different from that after removal of a load. Most previous studies have been conducted on unloaded specimens because in most cases it is difficult to perform chloride diffusion or migration tests on concrete specimens under loading conditions. However, the characteristics of cracks in loaded concrete are different from those in unloaded concrete, because cracks close back partially or even completely when unloading. So it is important to take into account the mechanical load to reflect the actual service condition of concrete structures. Gowripalan et al. (2000) studied the influence of flexural loading on the chloride resistance of concrete. Their results showed that the chloride diffusion coefficient was around $10 \%$ higher in the tensile region and around $25 \%$ lower in the compressive region than in a non-loaded specimen. This was explained by load-induced cracks appearing at the aggregate-paste interface in the tension zone, and the reduction in the porosity of the concrete in the compression zone.

\subsection{Limitations of experimental study}

Experimental studies have revealed the effect of cracks on the chloride transport properties of concrete to some extent. However, experimental measurements are almost always imperfect and subject to significant uncertainties and errors. Human influences and operator errors are inevitable during experiments. Even small variations in temperature and humidity can influence experimental results. Hence, sometimes, when the effect of one particular factor is studied by experiment, it is very difficult to avoid the influences of all the other factors. Moreover, even with the leadingedge technology today, some experiments are still very difficult or even impossible to perform. 
When studying the effect of cracks on the chloride transport properties of concrete by experiment, the difficulty lies in the creation of desirable cracks. Artificial cracks are easier to create, but they do not exactly reflect reality. For cracks induced by loading, variation in the crack geometry always exists. For instance, when studying the effect of crack width, cracks of a particular width can be created with experiments, but the crack geometries will not be exactly the same for cracks of the same width. The chloride transport process in a crack is not only influenced by crack width but also by the tortuosity, connectivity and surface roughness of the crack. It is impossible to control all these parameters in experiments. So it is very difficult to eliminate the influences of other factors and focus on the effect of crack width in an experiment. Thus, due to the difficulties in generating desirable crack geometry, currently, it is almost impossible to investigate the influences of crack tortuosity, connectivity, and surface roughness on the chloride transport properties of cracked concrete by experiment. In these circumstances, numerical simulation might be a good solution.

\section{Numerical simulations}

With the development of computer technology, numerical simulation has been more widely used in concrete research. Simulation has been considered as a helpful tool to reduce experimental time and cost, and plays an important role in research when experiments are difficult or even impossible to perform (Pritsker, 1989; Guala, 2002; Greenwald, 2004). Moreover, simulation can be applied to evaluate the influence of one single factor, eliminating influences of other factors which may be induced in experiments. It is widely accepted that experiment and simulation are different but complementary methodologies (Greenwald, 2004; Marsavina et al., 2009).

Several simulation studies have been conducted on the chloride transport process in cracked concrete (Kato et al., 2005; Wang et al., 2008; Marsavina et al., 2009; Ishida et al., 2009; Jin et al., 2010; Wang and Ueda, 2011; Lu et al., 2012; Bentz et al., 2013; Šavija et al., 2013). With simulation, the chloride transport process can be clearly represented, and the influences of different factors can be better revealed. It is helpful for us to understand the transport phe- nomenon itself. Moreover, a simulated chloride transport process could facilitate prediction of the service life of cracked concrete structures subjected to chloride environments.

Normally, the chloride transport process in cracked concrete can be simulated in three steps as shown in Fig. 2.

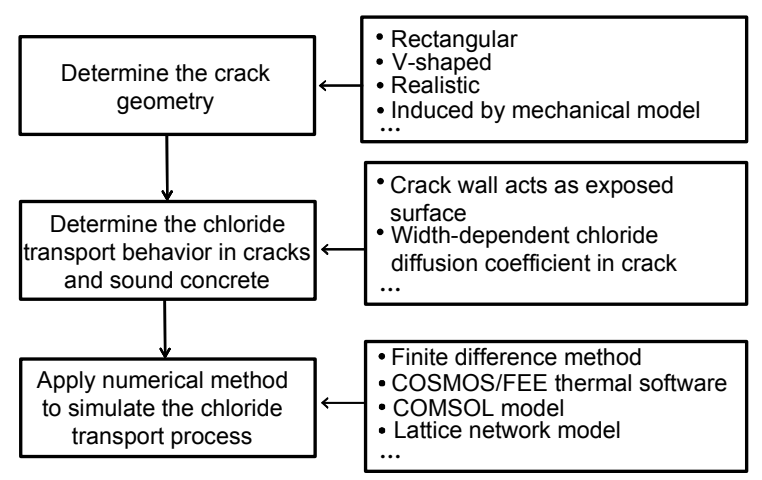

Fig. 2 Procedures to simulate the chloride transport process in cracked concrete

Details of simulation approaches are given in the following sections.

\subsection{Rectangular crack: cracking wall acts as an exposed surface}

To compare simulation results with experimental results, rectangular cracks are always employed in simulations. This is because in experiments rectangular artificial cracks of pre-defined width and depth can be easily produced. Marsavina et al. (2009) studied the influence of crack width and depth on the chloride penetration process in cracked concrete by both experiment and simulation. In the experiment, the cracks were made by positioning and removal of thin copper sheets inside specimens. The crack widths under investigation were $0.2 \mathrm{~mm}, 0.3 \mathrm{~mm}$ and $0.5 \mathrm{~mm}$, which may be wider than the upper critical value for crack width, as discussed in Section 2.3.1. Based on the experimental results, they concluded that the cracks behave like exposed concrete surfaces and the crack width does not affect the chloride penetration depth. When simulating the chloride penetration process in cracked concrete in these circumstances, the cracking walls were considered to be the same as concrete surfaces exposed to chloride solution. The influence of crack width was not considered in their simulation. The chloride diffusion coefficient 
in sound concrete was determined by a non-steadystate migration test. COSMOS/FEE thermal software, which is a finite element program, was used to simulate the chloride penetration process in the concrete specimen. The simulation results agreed fairly well with the experimental results from the migration tests.

This simulation could precisely predict the chloride penetration process in cases in which the concrete had cracks wider than the upper critical value. However, in reality, this is not always the case. Small cracks also exist in concrete. Hence, the influence of small cracks on the chloride transport process in cracked concrete should be taken into account in the simulation.

\subsection{Rectangular cracks: width-dependent chlo- ride diffusion coefficient in the cracks}

Experimental results have shown that crack width influences the chloride diffusion coefficient in the crack (Djerbi et al., 2008). This conclusion was adopted in the simulations and the relationship between the crack width and the chloride diffusion coefficient in the crack was established for the simulations.

Jin et al. (2010) proposed a model of the chloride transport process in cracked concrete based on experimental results and Fick's second law of diffusion. The data reported by Djerbi et al. (2008) were used to fit the formulation, in which the chloride diffusion coefficient in the crack was determined by the crack width. The crack was assumed to be rectangular. Fig. 3 shows the chloride diffusion process in cracks with different widths and in cracked concrete.

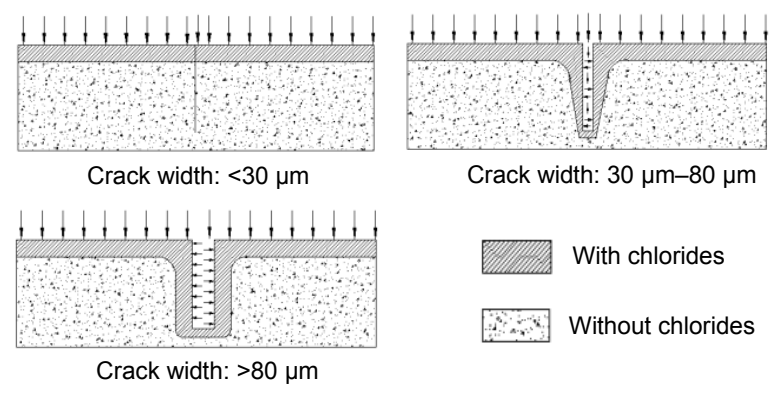

Fig. 3 Chloride diffusion process in cracks with different widths and in cracked concrete. Reproduced from (Jin et al., 2010), Copyright 2010, with permission from Korea Concrete Institute

When the crack width was smaller than $30 \mu \mathrm{m}$, the crack's effect on the chloride transport process in cracked concrete was ignored. The analytical solution to Fick's second law was used to describe the chloride diffusion process in the concrete. When the crack width was in the range of $30 \mu \mathrm{m}$ to $80 \mu \mathrm{m}$, the crack's effect was considered. The chloride diffusion process in the crack was considered as diffusion in a solution whose chloride diffusion coefficient is determined by the crack width. The chloride concentration at the crack surface was different from that at the exposed concrete surface. In the simulation, it was calculated by

$$
C_{\mathrm{s}}^{\mathrm{cr}}(y, t)=C_{\mathrm{s}} \times\left[1-\operatorname{erf}\left(\frac{y}{2 \sqrt{D_{\mathrm{cr}} t}}\right)\right],
$$

where $C_{\mathrm{s}}{ }^{\text {cr }}$ is the chloride concentration at the crack surface, $C_{\mathrm{s}}$ is the chloride concentration at the exposed concrete surface, $y$ is the depth from the exposed surface, $D_{\mathrm{cr}}$ is the chloride diffusion coefficient in the crack, and $t$ is the time. Under this condition, the finite element method was applied to simulate the chloride diffusion process. When the crack was wider than $80 \mu \mathrm{m}$, the crack wall was considered to be the same as an exposed concrete surface. An analytical solution to Fick's second law in 2D was used to calculate the chloride profile in cracked concrete.

Wang and Ueda (2011) proposed a mesoscale model of the chloride diffusion process in cracks and cracked concrete based on a lattice network model. The chloride diffusion coefficients in cracks with different widths were obtained by fitting experimental results. A Crank-Nicholson finite-difference algorithm (Crank, 1995) was used to solve Fick's second law in the whole domain. This model could be extended for V-shaped and multiple cracks. The influence of transverse cracks on chloride diffusion into concrete was simulated by Bentz et al. (2013), and the influence of chloride binding was also considered in their simulation. The chloride diffusion process was simulated with the COMSOL model. Ishida et al. (2009) modeled chloride diffusivity coupled with the non-linear binding capacity in cracked concrete based on the DuCOM model. In this model, the crack was considered as a transport path, the same as pores in concrete. The chloride transport due to convection currents generated by temperature or small hydraulic pressure gradients was also taken into account. 


\subsection{Realistic cracks: width-dependent chloride diffusion coefficient in the cracks}

In previous studies, rectangular shaped cracks were considered in simulations of the chloride transport process in cracked concrete. However, rectangular shaped cracks do not represent the real shape of cracks. So Lu et al. (2012) simulated the chloride transport process in cracked concrete with a real crack geometry reconstructed from X-ray computed tomography (CT) images. The resolution of the reconstructed 3D structure was $17 \mu \mathrm{m}$. The image-based structure of cracked concrete was converted into a finite element mesh. The chloride penetration process was simulated using the COMSOL model. The simulation was first validated with experimental results from micro-X-ray fluorescence (XRF) measurement, which could detect the chloride concentration in the concrete sample. Based on the 3D X-ray CT microstructure, the simulation of the chloride transport process was performed. The simulated chloride concentration contour in cracked concrete at $30 \mathrm{~d}$ can be seen in Fig. 4.

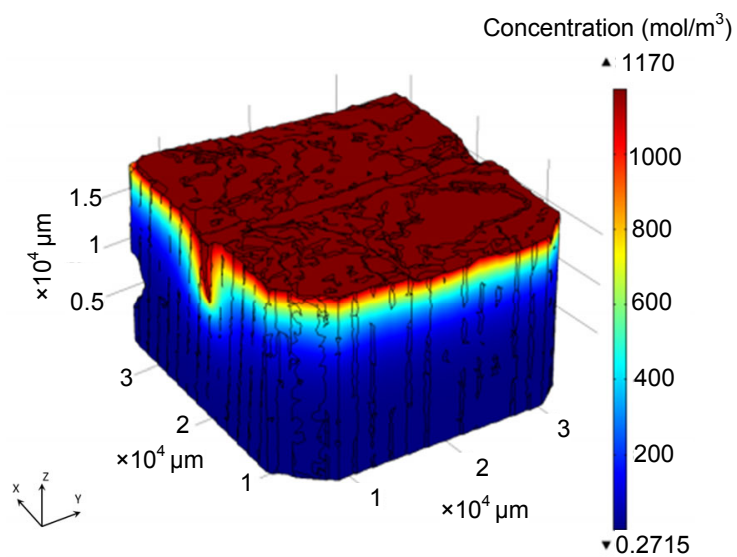

Fig. 4 Simulated chloride concentration contour in cracked concrete at $30 \mathrm{~d}$. Reprinted from (Lu et al., 2012), with permission from Prof. Dale P. BENTZ

Besides the X-ray CT structure, a virtual cracked concrete structure (Qian, 2012), containing irregular shaped aggregates, was built using a random particle placement program in their simulation. In the above simulations, the bulk concrete was always considered to be a homogeneous material, with one chloride diffusion coefficient. But actually, concrete is typically a heterogeneous material. Aggregates definitely influence the chloride transport process in the con- crete. With the COMSOL model, the chloride transport process in cracked heterogeneous concrete was accurately simulated by Lu et al. (2012). Fig. 5 shows the chloride concentration contour at a cutting plane in a virtual concrete structure at $30 \mathrm{~d}$. The effect of aggregates on the chloride distribution in cracked concrete can clearly be seen. Moreover, the chloride binding capacity was also considered in the simulation. Based on the simulation results, they concluded that cracks in concrete had an accelerating effect on the chloride penetration process, while sorption binding could retard the process.

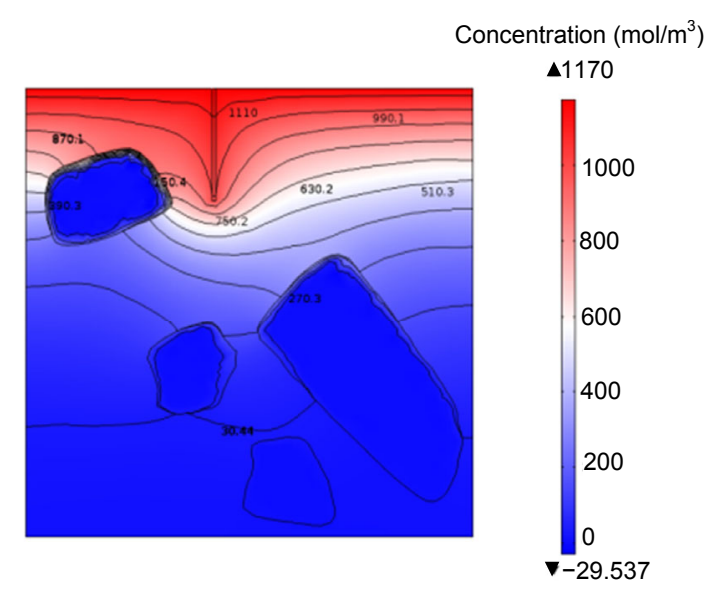

Fig. 5 Chloride concentration contour at a cutting plane of a virtual concrete structure at $30 \mathrm{~d}$. Reprinted from (Lu et al., 2012), with permission from Prof. Dale P. BENTZ

\subsection{Load induced cracks: width-dependent chlo- ride diffusion coefficient in the cracks}

Further progress on the simulation of the chloride transport process in cracked concrete was made by coupling the transport simulation with mechanical analysis. As discussed in Section 2.3.4, since the chloride transport process in concrete is influenced by the load condition, it is more realistic to study the chloride transport process in concrete when it is loaded. The pioneering simulation studies on this subject have been made by Wang et al. (2008) and Šavija et al. (2013).

Wang et al. (2008) simulated the chloride diffusivity of concrete based on a rigid body spring model (RBSM) and a truss network model. In this study, the concrete was simulated as a three phase material, i.e., aggregate particles, mortar and an interfacial transition zone (ITZ). The RBSM was employed to carry 
out the mechanical analysis to simulate the distribution and width of the cracks, which were induced by compressive or tensile loading. The truss network model was used to simulate the chloride transport process in cracked concrete. The formulation of the chloride diffusion coefficient in the crack with regard to the crack width was proposed by fitting the experimental results reported by Kato et al. (2005). The chloride diffusion coefficients of concrete under compression/tension at different stress levels were obtained using the proposed simulation method. The results showed that when the stress was above a critical level, the diffusion coefficient of the cracked concrete would increase rapidly. This tendency compared well with the experimental results.

Šavija et al. (2013) simulated the chloride diffusion process in sound and cracked concrete based on a lattice model. The concrete was considered to be composed of aggregates, mortar and ITZ, each represented by lattice elements. The mechanical simulation was performed using a lattice fracture model (Qian, 2012), and the chloride transport process was simulated using a lattice transport model. Four point bending simulations were performed on the mortar prisms with the lattice fracture model, and cracks with different widths were generated. Based on published data, the chloride diffusion coefficient in the crack was related to the crack width. Then the chloride diffusion process in cracked concrete was simulated. The simulation results showed good agreement with experimental results.

\section{Discussions and prospects}

Extensive experimental studies have been conducted on the chloride transport properties of cracked concrete. Different methods were used to produce the cracks and test the chloride transport properties of the specimens. Many influencing factors have been studied, such as crack width, crack depth, and external loading. A general conclusion is that the crack geometry is the key factor that influences the chloride transport process in the crack and cracked concrete. The crack geometry should include information on the width, depth, tortuosity, connectivity and surface roughness of the crack. Some studies have been performed on the effect of crack width on the chloride transport process. However, a consensus has not been reached on how the crack width influences the chloride transport process in the crack and cracked concrete. This demands further research. In addition, studies of the influences of tortuosity, connectivity and surface roughness of the crack on the chloride transport process in the crack and cracked concrete are also important.

The effects of self-healing, which can slow down the chloride transport process, should also be considered in further studies. Moreover, most experimental studies focused on the influence of discrete cracks (i.e., single crack) on the chloride transport properties of concrete. Very few studies have examined the effect of distributed cracks (i.e., crack networks), which could be induced, for example, by freeze-thaw cycles, alkali aggregate reaction, or fatigue (Langton, 2012). Fig. 6 shows typical distributed cracks caused by freeze-thaw damage to a concrete specimen. The relative dynamic Young's modulus of the specimen $\left(E / E_{0}\right)$ was 0.40 . Unlike a single crack, freeze-thaw damage is distributed relatively uniformly throughout the specimen. These connected cracks may have a much greater effect on the chloride transport properties of the concrete than discrete cracks.

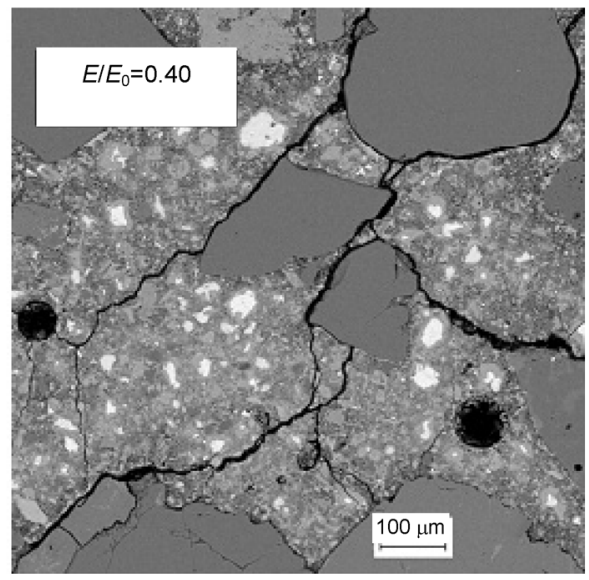

Fig. 6 Illustration of a crack network in a damaged freezethaw specimen from a scanning electron microscope image. Reprinted from (Yang et al., 2006), Copyright 2006, with permission from American Society of Civil Engineers

Several simulations of the chloride transport process in cracked concrete have been proposed. The influence of crack geometry on the chloride transport process is very difficult to study by experiment, but 
with simulation, the influence of crack geometry can be revealed. In simulation, any crack geometry can be defined by the authors. Hence, it is possible to study the influence of the tortuosity, connectivity and surface toughness of the crack on the chloride transport process in cracked concrete.

To be realistic, more progress on simulation has to be made. For instance, in simulations, some of the settings, such as the chloride diffusion coefficient in sound concrete, crack geometry, and surface chloride concentration, are set as constant during the chloride transport process. But in reality, the chloride diffusion coefficient of sound concrete should be a timedependent parameter, changing due to further hydration, carbonation or other chemical reactions. Also, cracks may evolve because of loading or self-healing. If possible, it is better to integrate these effects into the simulation.

Another essential input for the simulation is the chloride diffusion coefficient in the crack. Normally, this is determined by fitting experimental results, and is only related to the crack width. This is an empirical method. But actually, in a saturated crack, chlorides transport in the crack solution. The chloride transport speed is influenced by the solution itself, i.e., by the solvent and other ions in the solution. To determine the chloride diffusion coefficient in the crack from this point of view might be more reliable.

Another factor that significantly influences the chloride transport properties of cracked concrete is the degree of saturation of the concrete. The chloride transport mechanism in partly saturated concrete is very complicated. This is also an important topic for research. Finally, the simulation of the chloride transport process in concrete with distributed cracks is also a challenge.

\section{Conclusions}

For concrete structures exposed to chloride environments, the corrosion of reinforced steel is the major deterioration mechanism. In most cases, cracks exist in concrete structures and play an important role in their durability, and may especially affect the chloride transport properties of the concrete. Both experimental and simulation studies have been performed on the influence of cracks on the chloride transport process in cracked concrete. Many achievements have been made, providing significant insights on this phenomenon. The experimental studies show that the chloride transport properties of cracked concrete can be influenced by the crack width, crack depth, loading condition and the quality of the concrete. Many simulations on the chloride transport process have also been performed. The influences of several factors, including crack geometry and aggregates, on the chloride transport process in cracked concrete can be taken into account in simulations.

Although some progress have been made on this subject, further studies are still necessary. The mechanisms behind this phenomenon are still not clearly revealed. For instance, why the chloride diffusion coefficient in the crack is influenced by the crack width is unknown. Moreover, in practice, situations are much more complicated than experimental conditions and simulation settings. Other factors, such as carbonation, freeze-thaw, fatigue and saturation degree, will evidently influence the chloride transport process in cracked concrete. Further studies should be conducted on how these factors influence the chloride transport properties and deterioration mechanisms of cracked concrete, leading us closer to making reliable models for predicting the service life of real cracked concrete structures.

\section{Acknowledgements}

The authors would like to express their appreciation to Prof. Dale P. BENTZ, the National Institute of Standards and Technology, USA, for his help in this paper.

\section{References}

ACI 224.1R-07: 2007. Causes, Evaluation, and Repair of Cracks in Concrete Structures. American Concrete Institute, MI, USA.

Aiyastuti, S.M., 2005. Influence of Cracks on Chloride Induced Corrosion in Reinforced Concrete Fexural Members. PhD Thesis, University of New South Wales, Sydney, Australia.

Audenaert, K., De Schutter, G., Marsavina, L., 2009a. Influence of cracks and crack width on penetration depth of chlorides in concrete. European Journal of Environmental and Civil Engineering, 13(5):561-572. [doi:10.3166/EJECE.13. 561-572]

Audenaert, K., Marsavina, L., De Schutter, G., 2009b. Influence of cracks on the service life of concrete structures in a marine environment. Key Engineering Materials, 399: 153-160. [doi:10.4028/www.scientific.net/KEM.399.153]

Bentz, D.P., Garboczi, E.J., Lu, Y., et al., 2013. Modeling of the 
influence of transverse cracking on chloride penetration into concrete. Cement and Concrete Composites, 38:6574. [doi:10.1016/j.cemconcomp.2013.03.003]

Carino, N.J., Clifton, J.R., 1995. Prediction of cracking in reinforced concrete structures. Technical Report No. NISTIR 5634, Building and Fire Research Laboratory, National Institute of Standards and Technology, MD.

Crank, J., 1995. The Mathematics of Diffusion. Oxford Science Publications, London, England.

Djerbi, A., Bonnet, S., Khelidj, A., et al., 2008. Influence of traversing crack on chloride diffusion into concrete. $\mathrm{Ce}$ ment and Concrete Research, 38(6):877-883. [doi:10. 1016/j.cemconres.2007.10.007]

Gowripalan, N., Sirivivatnanon, V., Lima, C.C., 2000. Chloride diffusivity of concrete cracked in flexure. Cement and Concrete Research, 30(5):725-730. [doi:10.1016/S00088846(00)00216-7]

Greenwald, M., 2004. Beyond benchmarking-how experiments and simulations can work together in plasma physics. Computer Physics Communications, 164(1-3):1-8. [doi:10.1016/j.cpc.2004.06.001]

Guala, F., 2002. Models, simulations, and experiments. In: Magnani, L., Nersessian N.J. (Eds.), Model-based Reasoning. Springer USA, p.59-74. [doi:10.1007/978-1-46150605-8_4]

Ishida, T., Iqbal, P.O., Lan Anh, H.T., 2009. Modeling of chloride diffusivity coupled with non-linear binding capacity in sound and cracked concrete. Cement and Concrete Research, 39(10):913-923. [doi:10.1016/j. cemconres.2009.07.014]

Ismail, M., Toumi, A., Francois, R., et al., 2004. Effect of crack opening on the local diffusion of chloride in inert materials. Cement and Concrete Research, 34(4):711-716. [doi:10.1016/j.cemconres.2003.10.025]

Ismail, M., Toumi, A., Francois, R., et al., 2008. Effect of crack opening on the local diffusion of chloride in cracked mortar samples. Cement and Concrete Research, 38(8-9): 1106-1111. [doi:10.1016/j.cemconres.2008.03.009]

Jacobsen, S., Marchand, J., Boisvert, L., 1996. Effect of cracking and healing on chloride transport in OPC concrete. Cement and Concrete Research, 26(6):869-881. [doi:10.1016/0008-8846(96)00072-5]

Jin, W.L., Yan, Y.D., Wang, H.L., 2010. Chloride diffusion in the cracked concrete. In: Oh, B.H., Choi, O.C., Chung, L. (Eds.), Fracture Mechanics of Concrete and Concrete Structures-Assessment, Durability, Monitoring and Retrofitting of Concrete Structures. Korea Concrete Institute, Seoul, p.880-886.

Kato, E., Kato, Y., Uomoto, T., 2005. Development of simulation model of chloride ion transportation in cracked concrete. Journal of Advanced Concrete Technology, 3(1): 85-94. [doi:10.3151/jact.3.85]

Langton, C.A., 2012. Transport through cracked concrete: literature review. Technical Report No. SRNL-STI-201200267, Savannah River National Laboratory, Savannah River Nuclear Solutions, LLC, Aiken, SC, USA.
Leite, J., Slowik, V., Mihashi, H., 2004. Computer simulation of fracture processes of concrete using mesolevel models of lattice structures. Cement and Concrete Research, 34(6):1025-1033. [doi:10.1016/j.cemconres.2003.11.011]

Löfgren, I., Stang, H., Olesen, J.F., 2008. The WST method, a fracture mechanics test method for FRC. Materials and Structures, 41(1):197-211. [doi:10.1617/s11527-0079231-3]

Lu, Y., Garboczi, E., Bentz, D., et al., 2012. Modeling of chloride transport in cracked concrete: a 3-D image-based microstructure simulation. COMSOL Conference, Boston, USA, p.1-15.

Marsavina, L., Audenaert, K., De Schutter, G., et al., 2009. Experimental and numerical determination of the chloride penetration in cracked concrete. Construction and Building Materials, 23(1):264-274. [doi:10.1016/j. conbuildmat.2007.12.015]

Mehta, P.K., Monteiro, P.J.M., 2006. Concrete: Microstructure, Properties and Materials. McGraw-Hill Companies, New York, USA, p.176-179.

NT Building 355, 1997. Concrete, mortar and cement-based repair materials: chloride diffusion coefficient from migration cell experiments. Nordtest, Espoo, Finland.

NT Building 443, 1995. Concrete, hardened: accelerated chloride penetration. Nordtest, Espoo, Finland.

NT Building 492, 1999. Concrete, mortar and cement-based repair materials: chloride migration coefficient from non-steady state migration experiments. Nordtest, Espoo, Finland.

Pack, S.W., Jung, M.S., Song, H.W., et al., 2010. Prediction of time dependent chloride transport in concrete structures exposed to a marine environment. Cement and Concrete Research, 40(2):302-312. [doi:10.1016/j.cemconres.2009. 09.023]

Pease, B., Skocek, J., Geiker, M., et al., 2007. The wedge splitting test: influence of aggregate size and water-tocement ratio. International RILEM Workshop on Transport Mechanisms in Cracked Concrete, Ghent, Belgium. Acco, Leuven, p.111-122.

Pritsker, A.B., 1989. Why simulation works. The 1989 Winter Simulation Conference. Washington DC, USA. ACM Press, USA, p.1-6.

Qian, Z., 2012. Multiscale Modeling of Fracture Processes in Cementitious Materials. PhD Thesis, Delft University of Technology, Delft, the Netherlands.

Rocco, C., Guinea, G.V., Planas, J., et al., 2001. Review of the splitting-test standards from a fracture mechanics point of view. Cement and Concrete Research, 31(1):73-82. [doi:10.1016/S0008-8846(00)00425-7]

Rodriguez, O.G., Hooton, R.D., 2003. Influence of cracks on chloride ingress into concrete. ACI Materials Journal, 100(2):120-126. [doi:10.14359/12551]

Şahmaran, M., 2007. Effect of flexure induced transverse crack and self-healing on chloride diffusivity of reinforced mortar. Journal of Materials Science, 42(22):9131-9136. [doi:10.1007/s10853-007-1932-z] 
Šavija, B., Schlangen, E., 2012. Chloride ingress in cracked concrete - a literature review. Advances in Modeling Concrete Service Life: Proceedings of 4th International RILEM PhD Workshop, Madrid, Spain. Springer Netherlands, the Netherlands, p.133-142. [doi:10.1007/978-94007-2703-8_14]

Šavija, B., Pacheco, J., Schlangen, E., 2013. Lattice modeling of chloride diffusion in sound and cracked concrete. $\mathrm{Ce}$ ment and Concrete Composites, 42:30-40. [doi:10.1016/j. cemconcomp.2013.05.003]

Sillanpää, M., 2010. The Effect of Cracking on Chloride Diffusion in Concrete. MS Thesis, Aalto University, Espoo, Finland.

Song, H.W., Lee, C.H., Ann, K.Y., 2008. Factors influencing chloride transport in concrete structures exposed to marine environments. Cement and Concrete Composites, 30(2): 113-121. [doi:10.1016/j.cemconcomp.2007.09.005]

Wang, K., Jansen, D.C., Shah, S.P., et al., 1997. Permeability study of cracked concrete. Cement and Concrete Research, 27(3):381-393. [doi:10.1016/S0008-8846(97) 00031-8]

Wang, L., Ueda, T., 2011. Mesoscale modeling of the chloride diffusion in cracks and cracked concrete. Journal of Advanced Concrete Technology, 9(3):241-249. [doi:10. 3151/jact.9.241]

Wang, L., Soda, M., Ueda, T., 2008. Simulation of chloride diffusivity for cracked concrete based on RBSM and truss network model. Journal of Advanced Concrete Technology, 6(1):143-155. [doi:10.3151/jact.6.143]

Wang, Y., Li, L.Y., Page, C.L., 2005. Modelling of chloride ingress into concrete from a saline environment. Building and Environment, 40(12):1573-1582. [doi:10.1016/j. buildenv.2005.02.001]

Yang, Z., Weiss, W., Olek, J., 2006. Water transport in concrete damaged by tensile loading and freeze-thaw cycling. Journal of Materials in Civil Engineering, 18(3): 424-434.
[doi:10.1061/(ASCE)0899-1561(2006)18:3(424)]

Yoon, I.S., Schlangen, E., 2010. Long/Short term experimental study on chloride penetration in cracked concrete. Key Engineering Materials, 417-418:765-768. [doi:10.4028/ www.scientific.net/KEM.417-418.765]

Yoon, I.S., Schlangen, E., 2014. Experimental examination on chloride penetration through micro-crack in concrete. KSCE Journal of Civil Engineering, 18(1):188-198. [doi:10.1007/s12205-014-0196-9]

Yoon, I.S., Schlangen, E., De Rooij, M.R., et al., 2007. The effect of cracks on chloride penetration into concrete. Key Engineering Materials, 348-349:769-772. [doi:10.4028/ www.scientific.net/KEM.348-349.769]

Zhang, T., Gjørv, O.E., 1996. Diffusion behavior of chloride ions in concrete. Cement and Concrete Research, 26(6): 907-917. [doi:10.1016/0008-8846(96)00069-5]

\section{中文概要}

题 : 开裂混凝土氯离子传输性能研究综述: 实验研究 和计算机模拟

目 的: 综述开裂混凝土中氯离子传输性能的研究方法、 研究进展、最新研究成果和研究方向。

结 论: 实验研究和计算机模拟均表明开裂混凝土中氯离 子传输性能与裂缝形貌、混凝土组成和混凝土受 力状态等因素有关。现有研究虽已取得一定成 果, 但是仍需深入研究其他因素对开裂混凝土氯 离子传输性能的影响, 如冻融循环、疲劳和饱和 度等。在此基础上才能准确预测开裂混凝土结构 在氯盐环境中的服役寿命。

关键词: 混凝土; 裂缝; 氯离子传输性能; 实验研究; 计 算机模拟 